\title{
Defining upper gastrointestinal bleeding from linked primary and secondary care data and the effect on occurrence and 28 day mortality
}

\author{
Colin John Crooks ${ }^{1,2^{*}}$, Timothy Richard Card ${ }^{1,2}$ and Joe West ${ }^{1,2}$
}

\begin{abstract}
Background: Primary care records from the UK have frequently been used to identify episodes of upper gastrointestinal bleeding in studies of drug toxicity because of their comprehensive population coverage and longitudinal recording of prescriptions and diagnoses. Recent linkage within England of primary and secondary care data has augmented this data but the timing and coding of concurrent events, and how the definition of events in linked data effects occurrence and 28 day mortality is not known.

Methods: We used the recently linked English Hospital Episodes Statistics and General Practice Research Database, 1997-2010, to define events by; a specific upper gastrointestinal bleed code in either dataset, a specific bleed code in both datasets, or a less specific but plausible code from the linked dataset.

Results: This approach resulted in $81 \%$ of secondary care defined bleeds having a corresponding plausible code within 2 months in primary care. However only $62 \%$ of primary care defined bleeds had a corresponding plausible HES admission within 2 months. The more restrictive and specific case definitions excluded severe events and almost halved the 28 day case fatality when compared to broader and more sensitive definitions.

Conclusions: Restrictive definitions of gastrointestinal bleeding in linked datasets fail to capture the full heterogeneity in coding possible following complex clinical events. Conversely too broad a definition in primary care introduces events not severe enough to warrant hospital admission. Ignoring these issues may unwittingly introduce selection bias into a study's results.
\end{abstract}

Keywords: Selection bias, Mortality, Data linkage, Upper gastrointestinal bleeding, Case definitions

\section{Background}

Electronic health records of routinely recorded data are increasingly used in health research. They are relatively cheap, convenient, and provide power for studies that would be unfeasible in bespoke patient cohorts. Previously our group has used routine secondary care data (Hospital Episodes Statistics - HES) to define incidence and deprivation [1], and mortality trends [2] for upper gastrointestinal bleeding and we reassuringly found that the numbers of cases and procedures identified using HES were comparable to a national hospital audit [3].

\footnotetext{
*Correspondence: colin.crooks@nottingham.ac.uk

'Division of Epidemiology and Public Health, The University of Nottingham,

Clinical Sciences Building 2, City Hospital, Nottingham NG5 1PB, UK

${ }^{2}$ Nottingham Digestive Diseases Centre, National Institute for Health

Research Biomedical Research Unit, Queen's Medical Centre, Nottingham

University Hospitals National Health Service Trust, Nottingham NG7 2UH, UK
}

However for future studies investigating aetiological factors we require comprehensive prescription and comorbidity data for each patient prior to their hospital admission. As this was either unavailable or incomplete in secondary care data we planned to use primary care data (General Practice Research Database - GPRD) in which the coding for upper gastrointestinal bleeding was shown to be valid in $99 \%$ of cases by chart review [4]. To retain the advantages in using secondary care data of procedural coding, multiple hospital diagnoses, and accurate admission dates, we took the opportunity to use linked GPRD and HES data.

However our initial attempts to define a linked cohort of upper gastrointestinal bleeding demonstrated discrepancies in the cases detected between primary care and secondary care. We have therefore investigated the reasons

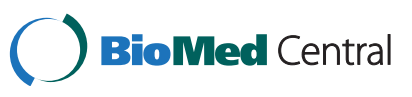


for this by studying alternative methods of defining cases (separately in each dataset or various combinations from both datasets) and to what extent the choice between these methods will affect our results.

\section{Methods \\ Databases \\ Hospital episodes statistics}

HES contains information on all admissions to an NHS hospital in England, with over 12 million new records added each year [5]. Each admission will have up to 20 diagnoses coded using the International Classification of Diseases 10th revision (ICD 10); and up to 24 procedures coded using the United Kingdom Tabular List of the Classification of Surgical Operations and Procedures (version OPCS4).

\section{General practice research database}

The GPRD contains longitudinal primary care data coded using the Read code system that are validated and individualised for over 46 million person years since 1987 [6]. The data are subject to quality checks and when the data are of high enough quality to be used in research they are referred to as "up to standard." The GPRD has been extensively validated for a wide range of chronic diagnoses and consistently found to be accurate [7-9]. This study was part of an ethical approval from the Independent Scientific Advisory Committee for MHRA database Research.

\section{Linkage}

The anonymised patient identifiers from GPRD, HES, and the Office of National Statistics (ONS) death register have been linked by a trusted third party using the NHS number, date of birth and gender [10]. As HES only covers English hospitals, any practices from Northern Island, Wales and Scotland were excluded. For this study we used the January 2011 download of GPRD GOLD data, in which $51.3 \%$ of GPRD primary care practices within England consented for their data to be linked.

\section{Defining upper gastrointestinal haemorrhage separately within primary care and secondary care data Defining cases in the general practice research database} Primary care bleed events were defined in GPRD using Read codes that indicated a definite diagnosis or symptom of upper gastrointestinal bleed. Codes for unspecified gastrointestinal bleeding were also included to be consistent with previously published ICD 10 code lists $[1,2,11]$, but they were excluded if they had a code for a lower gastrointestinal diagnosis or procedure. Primary care bleed events were excluded if the patient was under 18 years old, had temporary registration, had invalid date codes, was coded as elective or daycase, or occurred outside the observed and up to standard time period. The start of the observed and up to standard time period was defined as the latest of; the up to standard data collection date, 1st April 1997 (start of matching of GPRD and HES), or 3 months post current primary care registration (to avoid matching of prevalent events recorded during a new patient registration [12]). The end of this observed time period was defined by the earliest of; date of death, date of transfer out of practice, 31st August 2010 (end of matched HES data in current linkage) or the last collection date for the practice.

\section{Defining cases in the hospital episodes statistics database}

Secondary care bleed admissions were defined in HES using a published ICD 10 code list for upper gastrointestinal haemorrhage [11] and we further refined it by excluding unspecified gastrointestinal haemorrhage codes that also had either a lower gastrointestinal procedure or diagnosis coded [1,2]. Multiple admissions were included for each patient. Secondary care events were excluded if the patient was under 18 years old, had temporary registration in primary care, had invalid date codes, was coded as elective or daycase, or occurred outside the observed and up to standard time period as defined in the previous section for GPRD.

\section{Defining concurrent events in the linked databases Defining time windows for concurrent codes in primary and secondary care}

The timing of the coding of an event in primary and secondary care might differ due to communication delays. The standard within the NHS for hospital communications is that a discharge letter, with a minimum of the main discharge diagnosis and prescriptions, should be sent to the primary care doctor within 24 hours of discharge [13]. A time difference greater than 2 months was judged too long for delivery of discharge letters and its subsequent coding, and we therefore used 2 months as the cut off for associating separate events from the linked datasets. Other time windows, allowing for intermediate delays in primary care coding, were defined as less than 2 months, 1 month, 2 weeks, or 1 week, pre or post the event defined in either primary or secondary care. An event of upper gastrointestinal bleeding might have been coded first in either primary care prior to referral or in secondary care on the admission date. We therefore selected the earlier of the two dates as the index date for the 28 day case fatality analysis.

\section{Defining acceptable concurrent codes in primary and secondary care}

Upper gastrointestinal bleeding might not be identically coded in primary and secondary care because an upper gastrointestinal bleed code in one database could have a number of legitimate corresponding codes in the linked 
database: For example outcomes such as death or collapse, underlying diagnoses such as cancer, or procedures such as oesophagogastroduodenoscopy. To allow for this heterogeneity in coding, 'probable' and 'possible' groups of ICD 10 and Read codes were selected that could plausibly be coded following an upper gastrointestinal bleed. 'Probable' codes were defined as those specifying a likely symptom, cause, therapy, investigation or outcome of upper gastrointestinal haemorrhage. 'Possible' codes were defined as less specific codes that nevertheless indicated a non specific change in health state without indicating an alternative diagnosis to a gastrointestinal bleed (see Table 1 for categories of codes, 1=Most probable, 16=Less probable. The specific codes selected are listed in Additional file 1: Table S1 and Additional file 2: Table S2). This was based on the clinical judgement of the authors ( 2 consultant gastroenterologists and 1 trainee gastroenterologist).

\section{Classification of case definitions of upper gastrointestinal} bleeding in linked primary and secondary care data

We defined four case definitions of differing specificity and assessed how this altered our study population in regard to occurrence and case fatality. All four case definitions required at least a specific upper gastrointestinal bleeding code from one database with or without a code from the linked dataset that was of differing specificity; from the broad and sensitive case definition 1 that requires no linked code, to the restrictive and specific case definition 4 requiring a specific bleeding code. For each case definition cases initially defined from each dataset (identified as (a) for HES and (b) for GPRD) were pooled and duplicates excluded. Duplicate events were identified as those that occurred within the 2 month time window we used for defining corresponding codes.

- Definition 1-All secondary and primary care defined events

This broad and sensitive definition selected all possible cases of upper gastrointestinal bleeding from the linked data. All cases defined by a specific Read or ICD 10 bleed code in either database were combined and duplicate events were excluded.

- Definition 2a \& 2b-Primary and secondary care events that had a concurrent 'Probable' or 'Possible' code in the linked dataset.

This definition selected all cases of upper gastrointestinal bleeding that had either a supporting code (probable code) in the linked data or a less specific code (possible code) that did not

\begin{tabular}{|c|c|c|c|}
\hline $\begin{array}{l}\text { Category } \\
\text { Order }\end{array}$ & Group name & Group definition & $\begin{array}{l}\text { Probable or } \\
\text { possible codes }\end{array}$ \\
\hline 1 & Upper Gl bleed cause & $\begin{array}{l}\text { Code for known upper GI bleed diagnosis or cause. e.g. ulcer, oesophagitis, } \\
\text { NSAID or Aspirin use, cirrhosis, upper GI malignancy etc. }\end{array}$ & Probable \\
\hline 2 & Upper Gl bleed symptom & Symptoms indicating upper Gl bleed e.g. melaena, haematemesis etc. & Probable \\
\hline 3 & Upper Gl endoscopy & Any upper Gl endoscopy code (Not ERCP/EUS). & Probable \\
\hline 4 & Death (any cause) & Any code associated with death. & Probable \\
\hline 5 & Blood transfusion & Any code for blood transfusion or cross matching. & Probable \\
\hline 6 & Upper Gl procedure & $\begin{array}{l}\text { Any code for an upper Gl procedure plausible for managing a bleeding } \\
\text { episode. }\end{array}$ & Probable \\
\hline 7 & Gl bleed symptom & Any general code for Gl bleed (not specifically upper or lower). & Probable \\
\hline 8 & Upper GI diagnosis & $\begin{array}{l}\text { Any other code for an upper Gl pathology that might be associated with } \\
\text { an upper Gl bleed. }\end{array}$ & Possible \\
\hline 9 & Hospital & $\begin{array}{l}\text { Any code for referral, admission or discharge to hospital in a general or } \\
\text { related specialty. }\end{array}$ & Possible \\
\hline 10 & Upper Gl symptom & Any other code for symptoms of upper Gl pathology e.g. vomiting. & Possible \\
\hline 11 & $\begin{array}{l}\text { Gl symptom or } \\
\text { diagnosis }\end{array}$ & $\begin{array}{l}\text { Other Gl diagnoses or non specific Gl symptoms(e.g. pain) excluding lower } \\
\text { Gl symptoms. }\end{array}$ & Possible \\
\hline 12 & Alcohol & Any code indicating alcohol consumption or complications. & Possible \\
\hline 13 & Anaemia & Any code for anaemia excluding chronic deficiency anaemias and fatigue. & Possible \\
\hline 14 & Coagulation & $\begin{array}{l}\text { Any code indicating primary or secondary clotting abnormality, or use } \\
\text { of anti coagulation therapy. }\end{array}$ & Possible \\
\hline 15 & Collapse & Any code indicating collapse, fall or loss of consciousness. & Possible \\
\hline 16 & Other codes & Other codes specifying a change in health state with no specific diagnosis & Possible \\
\hline
\end{tabular}

Listed in Order of how Probable a Code Category Would be Associated with an Upper Gastrointestinal Haemorrhage Admission (1=Most Probable). 
contradict the bleeding diagnosis. Therefore for each upper gastrointestinal bleed defined in either dataset from definition 1, a specific bleed code, probable code or possible code was searched for in the linked dataset within the 2 month time window and selected in the hierarchical order of the categories listed in Table 1. Each primary care event was matched to only one hospital admission that was closest in time and vice versa.

- Definition 3a \& 3b-Primary and secondary care events that had a concurrent 'Probable' code in the linked database.

This definition selected all cases of upper gastrointestinal bleeding that had a code in the linked data that supported the diagnosis of bleeding. This required restricting the cases defined in $2 a$ \& $2 \mathrm{~b}$ to only those with a more specific probable code in the linked dataset.

- Definition 4-Primary and secondary care events with specific bleed codes in both GPRD and HES To provide a very specific case definition only those with a specific upper gastrointestinal bleed code in both primary and secondary care datasets were selected.

\section{Analysis: Incidence and $\mathbf{2 8}$ day case fatality by case definition}

The incidence was calculated per 100,000 person years; the denominator was the underlying number of person years contributed by patients registered in the GPRD and the numerator was calculated by pooling each of the case definitions from the GPRD and HES ((a) and (b) respectively for each of the definitions above).

Finally we assessed the effect of each of these case definitions on the results of our intended studies in linked primary and secondary care data. Within the general population registered to a linked GPRD primary care practice we calculated the numbers of cases identified by each case definition and the subsequent all cause 28 day case fatality. Dates of all deaths within 28 days following an upper gastrointestinal bleed admission date or primary care event date were ascertained using the linkage between the GPRD primary care practices and the UK Office for National Statistics death register.

\section{Results}

Defining upper gastrointestinal bleeding separately within primary care and secondary care data

Between 1st April 1997 and 30th August 2010 30,176 acute upper gastrointestinal bleed events were indentified in the linked primary care GPRD data by specific Read bleed codes (Table 2) and 26,964 acute upper gastrointestinal bleed admissions were identified in the linked secondary care HES data by specific ICD 10 bleed
Table 2 The frequency of read codes used to define upper gastrointestinal cases in the general practice research database

\begin{tabular}{|c|c|c|}
\hline Read code description & Read code & Frequency \\
\hline Haematemesis & $J 680.00$ & 10918 \\
\hline Melaena & J681.00 & 6957 \\
\hline GIB - Gastrointestinal bleeding & J68z.11 & 3464 \\
\hline Gastrointestinal haemorrhage & $J 68 . .00$ & 1203 \\
\hline Coffee ground vomit & $4 \mathrm{~A} 24.11$ & 968 \\
\hline Mallory - Weiss tear & $J 108.00$ & 755 \\
\hline Vomiting of blood & J680.11 & 494 \\
\hline Mallory-Weiss syndrome & $J 107.00$ & 427 \\
\hline Upper gastrointestinal haemorrhage & $J 68 z 200$ & 280 \\
\hline Oesophageal varices with bleeding & G850.00 & 211 \\
\hline C/O - melaena & 19E4.12 & 160 \\
\hline Acute haemorrhagic gastritis & $J 150000$ & 108 \\
\hline Blood in vomit - symptom & 1994.11 & 104 \\
\hline Blood in stools altered & J681.13 & 80 \\
\hline Bleeding acute gastric ulcer & $J 110111$ & 74 \\
\hline Bleeding chronic duodenal ulcer & $J 121111$ & 61 \\
\hline Gastric haemorrhage NOS & $J 68 z 000$ & 60 \\
\hline Gastrointestinal tract haemorrhage NOS & J68zz00 & 48 \\
\hline $\begin{array}{l}\text { Gastrointestinal haemorrhage } \\
\text { unspecified }\end{array}$ & J68z.00 & 33 \\
\hline Vomiting blood - fresh & 1994.00 & 30 \\
\hline Vomiting blood - coffee ground & 1995.00 & 30 \\
\hline $\begin{array}{l}\text { Unspecified duodenal ulcer with } \\
\text { haemorrhage }\end{array}$ & $\mathrm{J} 12 \mathrm{y} 100$ & 25 \\
\hline Intestinal haemorrhage NOS & $J 68 z 100$ & 23 \\
\hline $\begin{array}{l}\text { Acute duodenal ulcer with } \\
\text { haemorrhage }\end{array}$ & $J 120100$ & 19 \\
\hline Altered blood in stools & J681.12 & 18 \\
\hline Melaena - O/E of faeces & 4737.11 & 16 \\
\hline $\begin{array}{l}\text { Acute gastric ulcer with } \\
\text { haemorrhage }\end{array}$ & $J 110100$ & 13 \\
\hline Faeces colour: tarry & 4737.00 & 12 \\
\hline Vomit: coffee ground & $4 \mathrm{~A} 24.00$ & 12 \\
\hline Haemorrhage of oesophagus & J10y000 & 11 \\
\hline Aorto-duodenal fistula & G762000 & 7 \\
\hline Bleeding chronic gastric ulcer & 761D500 & 6 \\
\hline $\begin{array}{l}\text { Endoscopic injection haemostasis } \\
\text { of duodenal ulcer }\end{array}$ & $J 111111$ & 6 \\
\hline $\begin{array}{l}\text { Oversew of blood vessel of } \\
\text { duodenal ulcer }\end{array}$ & 7627200 & 4 \\
\hline $\begin{array}{l}\text { Gastrotomy and ligation of bleeding } \\
\text { point of stomach }\end{array}$ & $4 \mathrm{~A} 23.11$ & 3 \\
\hline Blood in vomit O/E & 7619100 & 3 \\
\hline Chronic duodenal ulcer with haemorrhage & $J 111100$ & 3 \\
\hline Chronic gastric ulcer with haemorrhage & $J 121100$ & 3 \\
\hline
\end{tabular}




\begin{abstract}
Table 2 The frequency of read codes used to define upper gastrointestinal cases in the general practice research database (Continued)
\end{abstract}

\begin{tabular}{lll}
\hline $\begin{array}{l}\text { Acute duodenal ulcer with haemorrhage } \\
\text { and perforation }\end{array}$ & 4 A23.00 & 2 \\
Chronic peptic ulcer with haemorrhage & J11y100 & 2 \\
Vomit: frank blood present & J120300 & 2 \\
$\begin{array}{l}\text { Unspecified gastric ulcer with haemorrhage } \\
\text { Unspec duodenal ulcer; unspec haemorrhage }\end{array}$ & J131100 & 2 \\
$\begin{array}{l}\text { and/or perforation } \\
\text { Unspecified peptic ulcer with haemorrhage }\end{array}$ & J12y300 & 1 \\
$\begin{array}{l}\text { Chronic gastric ulcer with haemorrhage } \\
\text { and perforation }\end{array}$ & J12yy00 & 1 \\
$\begin{array}{l}\text { Unspecified duodenal ulcer with } \\
\text { haemorrhage and perforation }\end{array}$ & J13y100 & 1 \\
\begin{tabular}{l} 
Total \\
\hline
\end{tabular} & & 26661 \\
\hline
\end{tabular}

codes (Table 3). Combining these events and excluding duplicates defined 45,472 unique upper gastrointestinal bleed events, $26 \%$ with a specific code in both datasets, $34 \%$ with a code only in HES and $41 \%$ with a code only in GPRD. The proportion of all events defined by specific bleed codes from both databases varied by year between $22 \%-27 \%$ but there was no clear trend over time.

\section{Classification of case definitions of upper gastrointestinal bleeding in primary and secondary care}

The flow chart in Figure 1 shows the selection of adult upper gastrointestinal bleeding events for each of our four case definitions. The percentages given in the flow chart are of the 45,472 pooled unique events in box 1 . Of the 26,964 secondary care defined bleeds in box 1a, $81 \%$ had a 'Probable' or 'Possible' code in primary care within 2 months (box 2a, Figure 1). By comparison 62\% of the 30,176 primary care defined bleeds in box $1 \mathrm{~b}$ had a 'Probable' or 'Possible' secondary care code within 2 months (box 2b, Figure 1). Further details of the timings of the closest 'Possible' or 'Probable' codes to the defining upper gastrointestinal bleed code date are shown in Tables 4 \& 5.

\section{Incidence and 28 day all cause case fatality by case definition}

Incidence was calculated for each of the pooled case definitions and these are shown in Table 6. Incidence followed a similar pattern to the crude numbers in Figure 1.

4,916 deaths were identified within 28 days of a bleed event using the linked ONS death register. 28 day mortality was calculated for each of the different case selections (Figure 2). Secondary care defined events had almost twice the case fatality of primary care defined
Table 3 The frequency of ICD 10 codes used to define upper gastrointestinal cases in the hospital episodes statistics database

\begin{tabular}{|c|c|c|}
\hline ICD 10 description & ICD 10 & Frequency \\
\hline Haematemesis & K920 & 9359 \\
\hline Melaena & K921 & 5802 \\
\hline Gastrointestinal haemorrhage unspecified & K922 & 4014 \\
\hline $\begin{array}{l}\text { Duodenal ulcer chronic or unspecified with } \\
\text { haemorrhage }\end{array}$ & K264 & 1333 \\
\hline $\begin{array}{l}\text { Gastro-oesophageal laceration-haemorrhage } \\
\text { syndrome }\end{array}$ & K226 & 1171 \\
\hline $\begin{array}{l}\text { Gastric ulcer chronic or unspecified with } \\
\text { haemorrhage }\end{array}$ & K254 & 1038 \\
\hline Duodenal ulcer acute with haemorrhage & K260 & 529 \\
\hline Acute haemorrhagic gastritis & K290 & 525 \\
\hline Oesophageal varices with bleeding & 1850 & 517 \\
\hline Haemorrhage of oesophagus & K228 & 483 \\
\hline Gastric ulcer acute with haemorrhage & K250 & 399 \\
\hline $\begin{array}{l}\text { Peptic ulcer chronic or unspecified with both } \\
\text { haemorrhage and perforation }\end{array}$ & K274 & 88 \\
\hline $\begin{array}{l}\text { Duodenal ulcer chronic or unspecified with } \\
\text { haemorrhage }\end{array}$ & K266 & 81 \\
\hline $\begin{array}{l}\text { Duodenal ulcer acute with both haemorrhage } \\
\text { and perforation }\end{array}$ & K262 & 38 \\
\hline $\begin{array}{l}\text { Gastric ulcer acute with chronic or unspecified } \\
\text { with both haemorrhage and perforation }\end{array}$ & K256 & 31 \\
\hline Peptic ulcer acute with haemorrhage & K270 & 20 \\
\hline $\begin{array}{l}\text { Gastric ulcer acute with both haemorrhage } \\
\text { and perforation }\end{array}$ & K252 & 17 \\
\hline $\begin{array}{l}\text { Gastrojejunal ulcer chronic or unspecified } \\
\text { with haemorrhage }\end{array}$ & K284 & 14 \\
\hline Gastrojejunal ulcer acute with haemorrhage & K280 & 6 \\
\hline $\begin{array}{l}\text { Peptic ulcer chronic or unspecified with } \\
\text { haemorrhage }\end{array}$ & K276 & 3 \\
\hline $\begin{array}{l}\text { Gastrojejunal ulcer chronic or unspecified } \\
\text { with haemorrhage }\end{array}$ & K286 & 2 \\
\hline $\begin{array}{l}\text { Gastrojejunal ulcer with both haemorrhage } \\
\text { and perforation }\end{array}$ & K282 & 1 \\
\hline Total & & 25471 \\
\hline
\end{tabular}

events; $13.1 \%$ compared to $7.7 \%$ (box (1a) versus box (1b) in Figure 2).

Overall 28 day case fatality for all events defined in either GPRD or HES was $10.8 \%$ (box (1)). Selecting events from the combined datasets with an associated 'Probable' or 'Possible' code reduced the 28 day case fatality slightly (10.3\%, box (2)) in Figure 2). Restricting the events to only those with a 'Probable' code had minimal affect on case fatality $(10.5 \%$, box (3)) in Figure 2$)$. However further restricting events to those that were defined by specific upper gastrointestinal haemorrhage codes in both primary and secondary care was associated with a much lower case 
(1) 45472 Unique acute upper GI bleed admissions defined in HES and/or GPRD

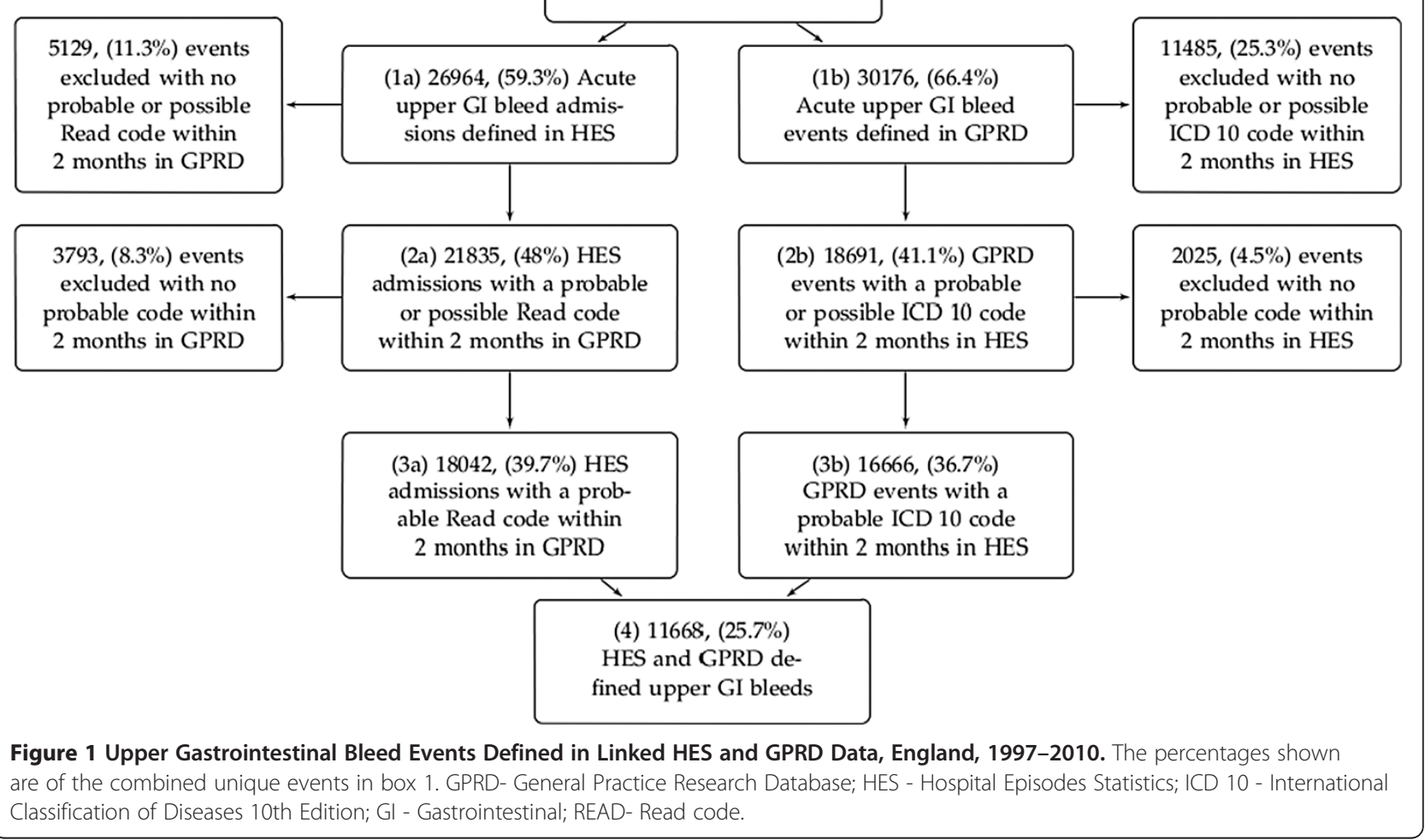

fatality (8.1\%, box (4) compared to $10.5 \%$, box (3)) in Figure 2).

\section{Discussion}

This study assessed the effect of different case definitions of upper gastrointestinal bleeding on its measured incidence and mortality in linked primary and secondary care data. We used the record linkage between the world's largest hospital admissions databases and one of the most commonly used primary care databases from

Table 4 Timing of probable or possible primary care events to secondary care defined upper gastrointestinal bleed admissions

\begin{tabular}{lccc}
\hline $\begin{array}{l}\text { Time difference between } \\
\text { defining hospital event and } \\
\text { closest probable or possible } \\
\text { primary care event }\end{array}$ & Frequency & Percentage & $\begin{array}{c}\text { Cumulative } \\
\text { percentage }\end{array}$ \\
\hline Exact match & 17,032 & 63.17 & 63.17 \\
1 day prior or 1 week post & 2,010 & 7.45 & 70.62 \\
2 weeks pre or post event & 707 & 2.62 & 73.24 \\
1 month pre or post event & 997 & 3.70 & 76.94 \\
2 months pre or post event & 1,089 & 4.04 & 80.98 \\
$>$ code months or no associated & 5,129 & 19.02 & 100.00 \\
Total & & & \\
\hline
\end{tabular}

the UK. Cases defined only in hospital data were at twice the risk of dying compared to those defined only in primary care data. Furthermore we found that the most specific case definition, which restricted to specific bleed codes from both datasets, excluded severe cases and resulted in a lower 28 day case fatality. In contrast the more sensitive case definitions, using the broader possible or probable code lists, retained the more severe cases and did not reduce the overall case fatality.

Table 5 Timing of probable or possible secondary care events to primary care defined upper gastrointestinal bleed events

\begin{tabular}{lccc}
\hline $\begin{array}{l}\text { Time difference between } \\
\text { defining primary care event } \\
\text { and closest probable or } \\
\text { possible secondary care }\end{array}$ & Frequency & Percentage & $\begin{array}{l}\text { Cumulative } \\
\text { percentage }\end{array}$ \\
event & & & \\
\hline Exact match & 15,689 & 51.99 & 52.99 \\
1 day prior or 1 week post & 1,348 & 4.47 & 56.46 \\
2 weeks pre or post event & 469 & 1.55 & 58.01 \\
1 month pre or post event & 612 & 2.03 & 60.04 \\
2 months pre or post event & 573 & 1.90 & 61.94 \\
$>2$ months or no associated & 11,485 & 38.06 & 100.00 \\
code & & & \\
Total & 30,176 & 100.00 & \\
\hline
\end{tabular}


Table 6 Pooled incidence for each case definition per 100,000 person years

\begin{tabular}{lll}
\hline $\begin{array}{l}\text { Pooled case } \\
\text { definitions }\end{array}$ & $\begin{array}{l}\text { Incidence per } \\
\mathbf{1 0 0 , 0 0 0}\end{array}$ & $\begin{array}{l}\mathbf{9 5 \%} \text { confidence } \\
\text { interval }\end{array}$ \\
\hline $1 \mathrm{a} \& 1 \mathrm{~b}$ & 224 & $(222-226)$ \\
$2 \mathrm{a} \& 2 \mathrm{~b}$ & 136 & $(134-138)$ \\
$3 \mathrm{a} \& 3 \mathrm{~b}$ & 114 & $(112-115)$ \\
$4 \mathrm{a} \& 4 \mathrm{~b}$ & 58 & $(57-59)$
\end{tabular}

(Pooled between GPRD defined cases and HES defined cases).

Therefore studies that are too restrictive in their case definitions will fail to capture the full heterogeneity of coding that follows complex or severe clinical events, and potentially introduce selection bias.

Reassuringly we found that $81 \%$ of upper gastrointestinal bleed events coded in secondary care had a probable or possible record in primary care within two months. However less than two thirds of upper gastrointestinal bleed events coded in primary care were associated with a hospital admission within the same time window. Therefore primary care could be recording sub acute bleeding episodes or symptoms that were historical at the time of the consultation, and therefore these patients did not require acute hospital admission. This is supported by the lower 28 day case fatality in events defined in GPRD alone compared to those also defined in HES. Coded bleeding events with no hospital admission were potentially interesting to investigate but were not representative of the acute bleeds described in studies of upper gastrointestinal bleeding management $[14,15]$.

One of the limitations of this study is that the anonymisation of HES data prevents the validation of individual records against the original clinical chart records. Although this potentially leaves the database susceptible to accusations of poor coding quality $[16,17]$, the most recent government audit of selected samples of UK hospital data confirmed accuracy approaching 90\% [18]. Other comparisons have reported similar rates of procedure coding in HES compared to specialist databases $[19,20]$ and the incidence of peptic ulcer haemorrhage in HES (1992-1995) was to comparable to the 1993 regional BSG audit (32 v 29 per 100,000 per year respectively). Furthermore the recent prospective national audit in the UK recorded reassuringly similar numbers for upper gastrointestinal bleed hospital admissions and procedures as were recorded in HES over the same period [3] and the outcome measure of 28 day case fatality following admission was similar to previous national audits [21,22] and the whole of the HES database [2].

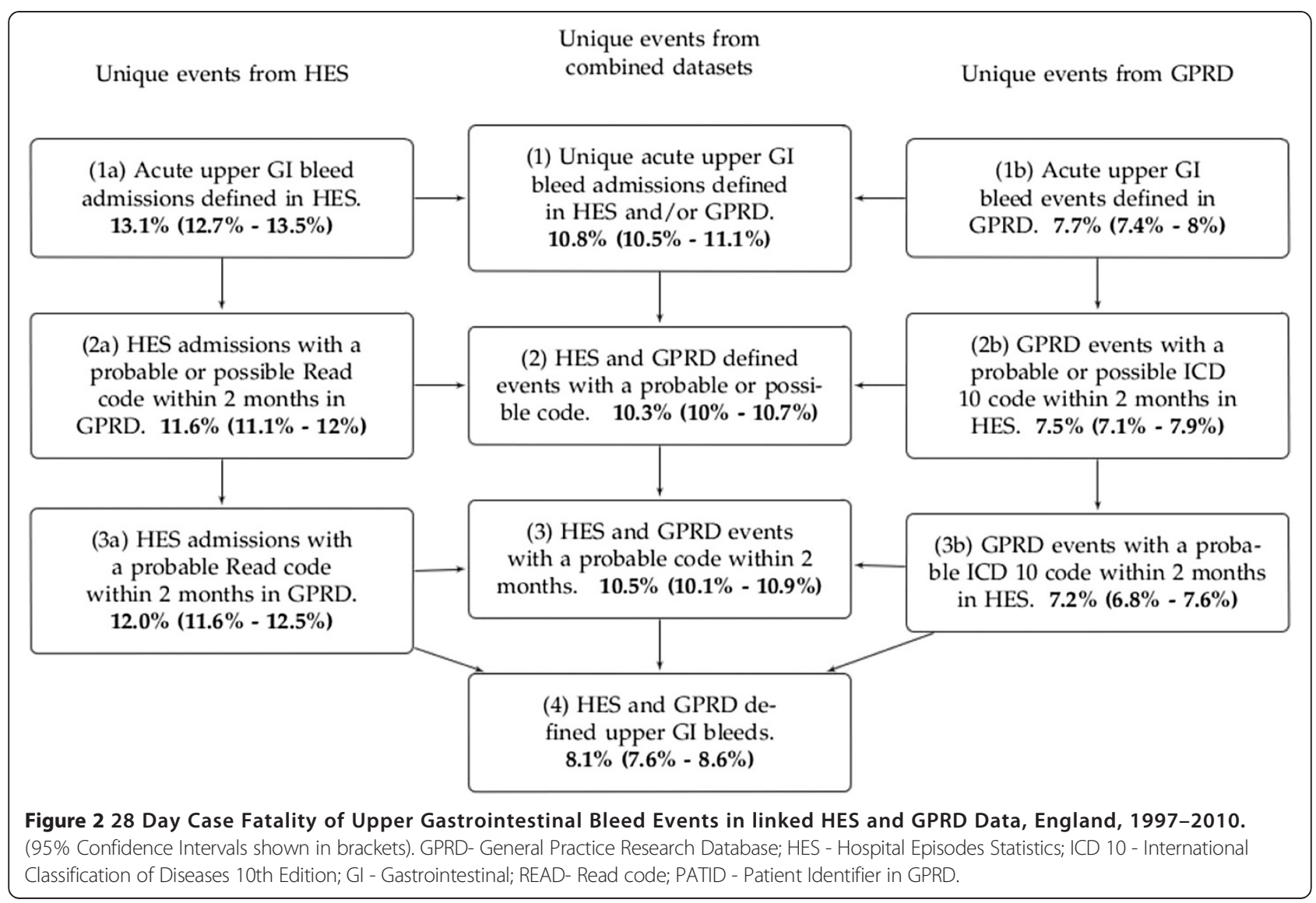


In the GPRD the positive predictive value of an upper gastrointestinal bleed coding was $99 \%$ using anonymised chart review [4]. However, we believe that the linkage of GPRD and HES, and the comparison presented in this paper, provides a more comprehensive and less biased assessment of the validity of the coding from both datasets than from small sample validation, as all potential cases were assessed and compared. Furthermore this linkage allows the comparison of coding by primary care doctors against the coding by trained hospital personnel using secondary care doctors' notes, thereby supporting any resulting case definitions from two separate and independent data sources.

There have been other databases linked for a range of purposes. However many, like those based on Health Maintenance Organisations, are limited by incomplete or selected population coverage because they are not based on a comprehensive population based primary health care system [23,24]. Scandinavian linked databases are the most established [25,26], but they do not have the richness of the data collection in primary care that the GPRD records, such as lifestyle factors, practice and individual socioeconomic status, occupation status, diagnoses, procedures, health promotion, and referrals. Prior to the linkage of HES and GPRD it was only possible to compare these databases using aggregate measures [27], and the new record level linkage avoids these ecological biases. The use of both primary and secondary care has previously been shown to be beneficial in defining chronic diseases such as diabetes [28,29], and using only primary care data reduced the positive predictive value for acute events [30]. Our study supports this finding for the acute event of upper gastrointestinal haemorrhage, and we propose that this issue can be addressed and improved upon by the use of linked hospital data.

We initially began this investigation to develop specific case definitions that minimise misclassification bias on effect estimates when testing aetiological hypotheses [31]. To achieve this we now intend to use a specific upper gastrointestinal bleed code in one dataset with a probable or specific code in the linked dataset (box 3a \& 3b, Figure 1). This will select the most plausible cases of acute upper gastrointestinal haemorrhage without excluding severe cases (box 3, Figure 2). In contrast to an aetiological study, studies that estimate incidence require a broader and more sensitive case definition to be sure of capturing all cases of the disease in question [31]. For incidence studies we therefore propose using all hospital defined cases with the addition of primary care defined cases that have a plausibly coded hospital admission (Figure 1, box (1a) and box (2b)). A sensitivity analysis that also included the events defined only in primary care (box 1b) would then provide an upper estimate of bleed events in the population. Equally for mortality studies a similar broad and sensitive definition might be preferable.

\section{Conclusions}

In this study we have been able to establish case definitions for upper gastrointestinal bleeding based on linked primary and secondary care data, and shown that linked data can be used to avoid excluding severe events. We have shown that hospital data was invaluable in accurately identifying acute bleeding events that were severe enough to require hospital admission, and the recent linkage with primary care introduced a wealth of long term diagnosis data and prescription data for the researcher. In addition there was a close match in timing in primary and secondary care between events coded for upper gastrointestinal haemorrhage. Finally we have shown that the choice of definition in linked data has a clear effect on the mortality of the chosen population. Our methods may not be generalisable to the definition of chronic diseases in linked databases, as chronic disease diagnoses are usually made in outpatient clinics and primary care. However we believe our findings are likely to be generalisable and relevant to other acute severe events, such as myocardial infarction or venous thromboembolism that are investigated, diagnosed, and managed during an acute hospital admission.

\section{Additional files}

Additional file 1: Table S1. Word document file containing a table of the ICD 10 supporting codes in each category and their frequency in this study.

Additional file 2: Table S2. Word document file containing a table of the Read supporting codes in each category and their frequency in this study.

\section{Competing interests}

The only competing interest is that Tim Card is married to an employee of AstraZeneca. Otherwise there are no potential competing interests to declare.

\section{Authors' contributions}

All authors were involved in the study concept, design, interpretation of results, and editing the manuscript. CC performed the data analysis and initial draft manuscript. All authors read and approved the final manuscript.

\section{Acknowledgements}

This work was supported by personal fellowships: Colin Crooks is supported by a Medical Research Council Population Health Scientist fellowship, Tim

Card is supported by the University of Nottingham, and Joe West is supported by a National Institute for Health Research/ University of Nottingham Senior Clinical Research fellowship. The funding bodies had no involvement in the study design, conduct, writing up or decision to publish.

Received: 17 May 2012 Accepted: 7 November 2012

Published: 13 November 2012 


\section{References}

1. Crooks CJ, West J, Card TR: Upper gastrointestinal haemorrhage and deprivation: a nationwide cohort study of health inequality in hospital admissions. Gut 2011, 61:514-520.

2. Crooks C, Card T, West J: Reductions in 28-day mortality following hospital admission for upper gastrointestinal hemorrhage. Gastroenterology 2011, 141(1):62-70.

3. Crooks CJ, West J, Hearnshaw SA, et al: Hospital admission database or specialist national audits for monitoring gastrointestinal bleeding? both are vital to monitoring our clinical practice. Gut 2011, 60(Suppl 1):A187. Abstract.

4. De Abajo FJ, Rodríguez LA, Montero D: Association between selective serotonin reuptake inhibitors and upper gastrointestinal bleeding: population based case-control study. BMJ 1999, 319(7217):1106-1109. Clinical research ed.

5. The Information Centre: HES Data Dictionary; 2009. http://www.hesonline. nhs.uk. Accessed 10/01/2012.

6. Walley T, Mantgani A: The UK general practice research database. Lancet 1997, 350(9084):1097-1099.

7. Jick H, Jick SS, Derby LE: Validation of information recorded on general practitioner based computerised data resource in the United Kingdom. BMJ 1991, 302(6779):766-768. Clinical research ed.

8. Hubbard R: Adult height and cryptogenic fibrosing alveolitis: a casecontrol study using the UK General Practice Research Database. Thorax 2000, 55(10):864-866.

9. Herrett E, Thomas SL, Schoonen WM, et al: Validation and validity of diagnoses in the general practice research database: a systematic review. Br J Clin Pharmacol 2010, 69(1):4-14.

10. Eaton SC, Williams TJ, Puri S, van Staa T: The feasibility of linking the English Hospital Episode Statistics to the GPRD. Pharmacoepidemiol Drug Saf 2008, 17:S214.

11. Button $L A$, Roberts $S E$, Evans $P A$, et al: Hospitalized incidence and case fatality for upper gastrointestinal bleeding from 1999 to 2007: a record linkage study. Aliment Pharmacol Ther 2011, 33(1):64-76.

12. Lewis JD, Bilker WB, Weinstein RB, et al: The relationship between time since registration and measured incidence rates in the General Practice Research Database. Pharmacoepidemiol Drug Saf 2005, 14(7):443-451.

13. Health and Social Care, Joint Unit: Discharge from hospital: pathway, process and practice, Health and Social Care Joint Unit and Change Agents Team; 2003. http://www.dh.gov.uk/en/Publicationsandstatistics/Publications/ PublicationsPolicyAndGuidance/DH_4003252. Accessed 10/01/2012.

14. Barkun ANN, Bardou M, Kuipers EJJ, et al: International consensus recommendations on the management of patients with nonvariceal upper gastrointestinal bleeding. Ann Intern Med 2010, 152(2):101-113.

15. Sung JJY, Chan FKL, Chen M, et al: Asia-Pacific Working Group consensus on non-variceal upper gastrointestinal bleeding. Gut 2011, 60(9):1170-1177.

16. Williams JG, Mann RY: Hospital episode statistics: time for clinicians to get involved? J R Coll Phys Clin Med 2002, 2(1):34-37.

17. Westaby S, Archer N, Manning N, et al: Comparison of hospital episode statistics and central cardiac audit database in public reporting of congenital heart surgery mortality. BMJ 2007, 335(7623):759.

18. Audit Commission: Improving data quality in the NHS Annual report on the PbR assurance programme. London: Audit Commission Publishing Team; 2010

19. Aylin P, Bottle A, Majeed A: Use of administrative data or clinical databases as predictors of risk of death in hospital: comparison of models. BMJ 2007, 334(7602):1044-1047.

20. Aylin $P$, Lees $T$, Baker $S$, et al: Descriptive study comparing routine hospital administrative data with the vascular society of great britain and ireland's national vascular database. Eur J Vasc Endovasc Surg 2007, 33(4):461-465

21. Rockall TA, Logan RF, Devlin $H B$, et al: Variation in outcome after acute upper gastrointestinal haemorrhage. The National Audit of Acute Upper Gastrointestinal Haemorrhage. Lancet 1995, 346(8971):346-350.

22. Hearnshaw SA, Logan RFA, Lowe $D$, et al: Acute upper gastrointestinal bleeding in the UK: patient characteristics, diagnoses and outcomes in the 2007 UK audit. Gut 2011, 60(10):1327-1335. doi:10.1136/ gut.2010.228437.

23. Selby JV: Linking automated databases for research in managed care settings. Ann Intern Med 1997, 127(8 Part 2):719.
24. Weissman JS, Hasnain-Wynia R: Advancing health care equity through improved data collection. N Engl J Med 2011, 364(24):2276-2277.

25. Olivarius NF, Hollnagel H, Krasnik A, Pedersen PA, Thorsen $\mathrm{H}$ : The danish national health service register. A tool for primary health care research. Dan Med Bull 1997, 44:449-453.

26. Furu K, Wettermark $B$, Andersen $M$, et al: The Nordic countries as a cohort for pharmacoepidemiological research. Basic Clin Pharmacol Toxicol 2010, 106(2):86-94.

27. Gupta D: Epidemiology of pneumothorax in England. Thorax 2000, 55(8):666-671.

28. Morgan AG, McAdam WA, Walmsley GL, et al: Clinical findings, early endoscopy, and multivariate analysis in patients bleeding from the upper gastrointestinal tract. Br Med J 1977, 2(6081):237-240.

29. Harvey JN: Estimation of the prevalence of diagnosed diabetes from primary care and secondary care source data: comparison of record linkage with capture-recapture analysis. J Epidemiol Community Health 2002, 56(1):18-23.

30. Khan NF, Harrison SE, Rose PW: Validity of diagnostic coding within the general practice research database: a systematic review. Br J Gen Pract 2010, 60(572):e128-e136.

31. Dicker RC: Designing studies in the field. In Field Epidemiology. 3rd edition. Edited by Gregg MB. 198 Madison Avenue, New York, New York 10016: Oxford University Press; 2008:141-142.

doi:10.1186/1472-6963-12-392

Cite this article as: Crooks et al:: Defining upper gastrointestinal bleeding from linked primary and secondary care data and the effect on occurrence and 28 day mortality. BMC Health Services Research 2012 12:392.

\section{Submit your next manuscript to BioMed Central and take full advantage of:}

- Convenient online submission

- Thorough peer review

- No space constraints or color figure charges

- Immediate publication on acceptance

- Inclusion in PubMed, CAS, Scopus and Google Scholar

- Research which is freely available for redistribution 